\title{
A Research on Asymmetric Inter Group Cooperation--A Lab Experiment with Two Global Public Goods
}

\author{
Zhan-Bing HUANG, Xiao MA, Ying LIU \\ International Business School, Shaanxi Normal University, Xi'an 710119, P. R. China \\ hzb10@163.com, 925404668@qq.com, 1548154844@qq.com
}

\begin{abstract}
Keywords: extrinsic reciprocity, heterogeneous income, intergroup cooperation, multiple public goods, voluntary contributions mechanism.
\end{abstract}

\begin{abstract}
We accomplished a linear public goods experiment to study the effects of extrinsic reciprocity, via comparing a setting where subjects have the same income with a setting where they differ. We find that: 1) The contribution is higher in the two global public goods treatment than in the single global public goods experiment; 2) The subjects contribute more to the local public goods than to the global public goods; 3) When MPCR (marginal per capita return) is heterogeneous, members have a stronger will to contribute to the public goods; 4) In a certain range, the greater the gap between MPCR the more conducive to the overall public goods contribution. Our findings suggest that policy interventions may be necessary to improving intergroup cooperation with heterogeneous income and multiple public goods.
\end{abstract}

\section{Introduction}

Intergroup cooperation is a common phenomenon in current economic life, but it is difficult to achieve effective cooperation in most areas because partners acquire asymmetric benefits from "cooperation". Therefore, understanding the impact of the income difference on both sides of the cooperation becomes the key factor that promotes the efficiency of cooperation.

Scholars did a lot public goods researches between individual and group social dilemma in the research process of intergroup cooperation. But traditional economics research is based on rationality assumption, which completely ignores human sociality, leading to the results that cannot fully explain the specific decision-making behavior. And behavior economics analyzes people's behavior under the assumption of "limited rationality". Combined with psychological factors they can more accurately explain the decision-making behavior of people. Since the data on cooperation are difficult to obtain in reality as well as the degree of uneven earnings and its consequences are hard to measure, laboratory experiment method has more advantages.

Therefore, we research the regional cooperation process based on regional economics and behavioral economics theory in this article by means of laboratory experiment by setting the asymmetric MPCR of differentiation under two global public goods to reflect asymmetric income. In the experimental environment we explore people's behavior cooperatively. Our findings not only contribute to the academic literature, but also help policymakers design regulatory policies under income heterogeneity. In particular, we demonstrate that extrinsic reciprocity can improve intergroup cooperation.

\section{Literature Review}

Many researchers have studied single public goods provision using laboratory experiments. Isaac, Walker and Thomas (1984), and Isaac and Walker (1988) pioneered the systemic research of MPCR. Schatzberg and Walker (1995) and Fellner, Iida, Kröger and Seki (2011) introduced heterogeneity into MPCRs of a public commodity, and find high MPCR-type subjects contribute more than low MPCR-type subjects. Subsequent experiments can be divided into two categories: direct and indirect research. A part of the experiments clearly study the effect of MPCR and take it as treatment variable called direct research (Isaac et al., 1984; Isaac and Walker, 1988; Isaac et al., 1994; Carpenter, 2007; Gunnthorsdottiretal., 2007). In this type of research, the mere difference 
between different experiments is only part of the MPCR. In addition to Isaac et al. (1994) the rest of the experimental results show that MPCR and public goods supply were significantly positively correlated. Other experiments study the MPCR in the indirect way (Marwell and Ames, 1979; Isaac et al., 1985; Chan et al., 1999; Cherry et al., 2005; Buckley and Croson, 2006). In this kind of study, subjects within the same group will face different MPCR, therefore explaining MPCR for comparison in the influence of individual public goods supply.

In addition, there are several studies that deal with multiple public goods under a voluntary contribution mechanism (VCM). Blackwell and McKee (2003) and Fellner and Lünser (2008) investigate the relationship of MPCR to the contribution to local and global public goods. Both studies find that when the global public goods is more socially efficient, subjects increase their global public goods contributions.

Overall, the empirical research for multiple public goods is insufficient because of the complexity of the experimental setup. These existing studies, however, have not addressed the effects of MPCR heterogeneity with multiple public goods. With multiple public goods, MPCR heterogeneity between local groups may cause a different pattern of contributions to local and global public goods. These different patterns may increase or decrease the overall contribution. To explore these complex issues and to find out whether public goods may be provided efficiently in such settings, we need to understand how people allocate their heterogeneous incomes between local and global public goods. In this paper, we introduce heterogeneous MPCR between local groups. Subjects can contribute not only to a local but also to two global public goods in our experiment.

\section{Experimental Design and Procedures}

We adopt VCM to investigate the effect of different MPCR on the individual decision making since it was widely used after Isaac、Walker and Thomas former work (1984) .This section provides the experimental design and procedures.

\section{Experimental Design}

The experiment is similar to a standard, linear public goods game in VCM except for the additional local and global public goods provision. There are 6 subjects in each global group, divided into two local groups of 3 subjects each. At the beginning of each period, each subject receives 40 tokens as an original endowment. In every period, each subject decides how to allocate their endowments between private goods, one local public goods, and two global public goods.

The benefit of one unit of private good is 1 for the subject who consumes this private good. On the other hand, local public goods provide benefits to all of its local group members, while the global public goods provide benefits to all members in the global group. In our experiment, we add one new global public goods (G2). In order to balance the benefits that individual receive from the two global public goods, we assume that the $\mathrm{MPCR}_{\mathrm{G} 11}=\mathrm{MPCR}_{\mathrm{G} 22}, \mathrm{MPCR}_{\mathrm{G} 12}=\mathrm{MPCR}_{\mathrm{G} 21}$.

The following equation (Eq. 1) describes the payoff function of subject $i$ in period $t$ :

$$
\pi_{i}=E-L-G_{1}-G_{2}+\theta \times \sum_{i=1}^{n} L i+\alpha \sum_{i=1}^{n} G 1 i+\beta \sum_{i=1}^{n} G 2 i
$$

where $E$ is the endowment of subject $i$ at period $t$ (the amount is fixed throughout the experiment), $\mathrm{L}$ is the amount of local public goods contribution by subject $\mathrm{i}$ at period $\mathrm{t}, \mathrm{G}_{1}$ is the amount of the first global public goods contribution by subject $i$ at period $t, G_{2}$ is the amount of the second global public goods contribution by subject $\mathrm{i}$ at period $\mathrm{t}, \mathrm{a}$ is the individual marginal per capita return from the global public goods in the $\mathrm{G} 1\left(\mathrm{MPCR}_{\mathrm{G} 1}\right)$ and $\beta$ is the individual marginal returns from the global public goods in the G2 $\left(\mathrm{MPCR}_{\mathrm{G} 2}\right)$.

Our experiment has three treatments and 6 sessions for each. The subjects participate in this local-global public goods game for 5 periods in each session, where the MPCR of a local public goods is $\mathrm{MPCR}_{\mathrm{L}}=0.5$ and the MPCR of a global public goods MPCR ${ }_{\mathrm{G}}$ depends on the treatments. Each session has four global groups divided into eight local groups, so that the number of subjects in the global group is 24 . Table.1 shows the specific experimental design. 
Table.1: Experimental Design - Local and Global Public Goods Game

\begin{tabular}{|c|c|c|c|c|c|c|c|c|}
\hline \multirow{2}{*}{$\begin{array}{l}\text { G } \\
L\end{array}$} & \multicolumn{2}{|c|}{ I } & \multicolumn{2}{|c|}{ II } & \multicolumn{2}{|c|}{ III } & \multicolumn{2}{|c|}{ IV } \\
\hline & 1 & 2 & 3 & 4 & 5 & 6 & 7 & 8 \\
\hline & & & & & 0.5 & 0.3 & 0.5 & 0.3 \\
\hline \multirow[t]{2}{*}{ MPCR } & & & & & 0.5 & 0.3 & 0.5 & 0.3 \\
\hline & 0.3 & 0.6 & 0.3 & 0.6 & 0.5 & 0.6 & 0.5 & 0.6 \\
\hline
\end{tabular}

Note: $\mathrm{G}$ in the Table means global group,L means local group.

\section{Procedures}

Three experiments were conducted in the economics lab of Shaanxi Normal University from December 2014 to November 2015 and 90 undergraduates from a wide range of disciplines participated in the study. For the accuracy of the data, we use real monetary stimuli and the average earnings of subjects were 25yuan. The experiment was programmed in z-Tree, Fischbacher (2007).

Subjects were seated separately in the laboratory room. Before starting the experiment, we distributed a copy of instructions which explained the whole procedure, the information structure, and the payoff scheme of each session. Then we read the instructions aloud to make sure the rules of each treatment were understood by all our subjects. We did not allow the subjects to communicate with each other during the session. Each session took one to two hours.

\section{Experimental Results}

The structure of this section is as follows. In subsection 4.1, we compare the single public goods treatment with the two public goods treatment. In subsection 4.2, we compare the MPCR heterogeneity in the two public goods treatment; in subsection 4.3, we explore the effect of gap between MPCR on intergroup cooperation.

\section{Contribution Differences between Single and Two Global Public Goods}

The experiment data was collected mainly in the context of nested dilemma. Now we compare this data with previously obtained data, namely the single global public goods experiment. We regard a group with different $\mathrm{MPCR}_{\mathrm{G}}$ between groups as the research object, namely local group 1 $\mathrm{MPCR}_{\mathrm{G} 11}=0.5$, group $2 \mathrm{MPCR}_{\mathrm{G} 12}=0.3$, we can draw the following data shown in Table. 2

Table.2: Average Token Contribution of Local and Global Public Goods

\begin{tabular}{llccc}
\hline \hline & \multicolumn{2}{c}{ contribution of local PG } & \multicolumn{2}{c}{ contribution of global PG } \\
\cline { 2 - 5 } Mean (rate) & \multicolumn{1}{c}{ Single PG } & two PG & Single PG & two PG \\
Global group & $10.5(26.28 \%)$ & $15.3(38.25 \%)$ & $7.06(17.65 \%)$ & $7.24(35.6 \%)$ \\
Local 1 & $11.12(27.8 \%)$ & $17.86(44.75 \%)$ & $8.5(21.35 \%)$ & $15.28(38.2 \%)$ \\
Local 2 & $9.9(24.75 \%)$ & $13.04(32.6 \%)$ & $5.58(13.95 \%)$ & $13.18(32.95 \%)$ \\
\hline \hline
\end{tabular}

Table. 2 shows the average contributions to the global public goods and to the local public goods. From Table.2, the average contribution to the global public goods appears obviously larger in the two global public goods treatment( 14.24 ) than in the single global public goods treatment(7.06), especially the contribution of local group $2\left(\mathrm{MPCR}_{\mathrm{G}}=0.3\right)$, which changed significantly from 5.58 to 13.18 , increasing by 7.6 . It also shows that with the increase of the number of global public goods, the contribution to local public goods keeps the same trend,but the growth of local group 1 is more obvious than in group 2. One possible explanation is that the group 2 contributed more to the global group to realize equilibrium of global cooperation. It proves that when there is one global public goods, the MPCR differences, namely the income asymmetric, is not conducive to people's cooperation, which can be explained by "equity theory" (Adams, 1965; Walster, Berscheid, \&Walster, 1973). While there are two global public goods, the contribution to the local and global 
public goods will increase, especially for those who return a set of smaller contribution in single public goods.

Then we perform T- test function from Stata software to test the hypothesis on the local and the global public goods contributions,using individual contribution per period as units of observation. Contribution difference is highly significant $(p<0.01)$ and it proves that the contribution is significantly higher in two global PG than in the single treatment.

Finding 1 (Efficiency). The contribution is higher in the two global public goods treatment than in the single global public goods experiment.

According to Table.2 we can observe that whether in a single global public goodsexperiment, or in the experiment of two global public goods, the team member's contribution to the local public goods value has been higher than group member's contribution to the global public goods. The results can be explained with social identity theory (Tajfel, Tuner, 1986). Social identity is individual identity that people not only own group attributes, but also know they can benefit from group members. In order to improve their social identity, individuals are more willing to give their initial endowment to small groups.

Finding 2: The subjects contribute more to the local public goods than to the global public goods.

\section{Effect of Asymmetric MPCR in the Experiment with Two Global Public Goods}

First of all, we choose those who take the symmetrical MPCR $\left(\operatorname{MPCR}_{\mathrm{G} 11}=\operatorname{MPCR}_{\mathrm{G} 12}=0.4\right)$ as control group, then analyze the contribution of groups with asymmetric MPCR (local group 1: $\mathrm{MPCR}_{\mathrm{G} 11}=0.5$, local group 2: MPCR $12=0.3$ ). We can get the following data in Table 3 .

When there is no difference in the MPCR $\left(\mathrm{MPCR}_{\mathrm{G} 11}=\mathrm{MPCR}_{\mathrm{G} 12}=0.4\right)$, the average contribution to the two global public goods( 11.62) is significantly different from the heterogeneous MPCR treatment $(14.24)$, namely $\mathrm{MPCR}_{\mathrm{G} 11}=0.5, \mathrm{MPCR}_{\mathrm{G} 12}=0.3$. Then we perform $\mathrm{T}$ - test function from Stata software to test the hypothesis on the effect of different MPCR and the results show that the difference is highly significant $(\mathrm{p}<0.01)$. Table.3 displays the details.

Table.3: Contribution to Global PG with Asymmetric MPCR

\begin{tabular}{lcl}
\hline \hline Mean & homogeneous MPCR $(0.4,0.4)$ & heterogeneous MPCR(0.5, 0.3) \\
\hline All members & $11.62(9.68)$ & $14.24(10.45)$ \\
local group 1 & $11.25(9.37)$ & $15.28(10.27)$ \\
local group 2 & $12(9.98)$ & $13.18(10.54)$ \\
\hline Mean & 11.62 & 14.18 \\
Sig & $0.000^{* * *}$ & $0.000^{* * *}$ \\
\hline
\end{tabular}

Note: Value in parentheses is the standard deviation ${ }^{* *} \mathrm{p}<0: 01,{ }^{* *} \mathrm{p}<0: 05,{ }^{*} \mathrm{p}<0: 1$

On the whole, this indicates that the contribution to the global public goods is higher in the heterogeneous treatment than in the homogeneous treatment in multiple global public goods.

Finding 3: When MPCR is heterogeneous, members' will of contribution to the global public goods is stronger in the two global public goods game.

\section{Impact of Asymmetric Degree on Individual Contribution in Two Global Public Goods}

Based on the previous analysis we concluded that asymmetric MPCR helps to cooperation, we infer a hypothesis: the greater the gap between the team, the more conducive to cooperation.

In order to investigate the hypothesis, we also conducted experiment that MPCR differences between groups are respectively 0.1 and 0.3 . Accordingly, we conducted three treatments: the gap between MPCR is 0.1, 0.2, 0.3, we get the following data: 
Table.4 Average contribution among heterogeneous MPCR

\begin{tabular}{rccc}
\hline MPCR & Obs & Gap & Mean PG \\
\hline 0.5-0.6(low gap) & 360 & 0.1 & 21.60 \\
0.5-0.3(mid-gap) & 1980 & 0.2 & 14.42 \\
0.6-0.3(high gap) & 360 & 0.3 & 20.91 \\
\hline
\end{tabular}

Overall, as we can see from the Table.4, when MPCR gap between groups increased from 0.1 and 0.2 , the contribution declined from 21.60 to 14.24 . But when the gap increased from 0.2 and 0.3 , the contribution increased from 14.24 to 20.91 , which is not in conformity with our hypothesis.

That's because marginal benefit from global public goods is very high in the low-gap treatment (0.5-0.6), so it's reasonable that the overall contribution is the highest.

In order to test our hypotheses, we perform Wilcoxon-Mann-Whitney rank sum test on pairwise comparison. Table. 5 shows the statistical results.

Table.5 Pairwise comparison of different gap

\begin{tabular}{r|l|l|c}
\hline gap & \multicolumn{1}{|c|}{0} & \multicolumn{1}{|c}{0.1} & 0.2 \\
\hline 0.1 & $\mathrm{z}=-2.803 \mathrm{p}=0.0051^{* * *}$ & & \\
\hline 0.2 & $\mathrm{z}=-1.886 \mathrm{p}=0.0593$ & $\mathrm{z}=2.805 \mathrm{p}=0.0050^{* * *}$ & \\
\hline 0.3 & $\mathrm{z}=-2.823 \mathrm{p}=0.003^{* * *}$ & $\mathrm{z}=2.705 \mathrm{p}=0.0050^{* * *}$ & $\mathrm{z}=-2.930 \mathrm{p}=0.002^{* * *}$ \\
\hline
\end{tabular}

${ }^{* * *} \mathrm{p}<0: 01,{ }^{* *} \mathrm{p}<0: 05,{ }^{*} \mathrm{p}<0: 1$, For a comparison results, the corresponding experimental linebureau is in front of the column bureau, so $\mathrm{Z}>0$ indicates the former is higher.

Through the contrast can be seen that, in addition to the treatment when gap is 0.2 , the contribution of other experimental groups are significantly different $(\mathrm{p}<0.01)$. At the same time, through the $z$ value in Table.8 we know the contribution is highest when the gap is 0.3 , the lowest when gap is 0.2 , and mediate when gap is 0.1 . Eliminate the low-gap treatment because of marginal revenue maximum set factors, the hypothesis is confirmed preliminarily. The bigger gap the greater the contribution.

We can explain this using extrinsic reciprocity. Generally speaking, when people obtain uneven income from cooperation in one field, those who gain less usually terminate cooperation. But when we introduce another available area for cooperation, those who got less benefit from previous cooperation may gain more interest in this cooperation, thus realizing the change of income from symmetric to symmetry and making sustained cooperation possible.

Finding 4: In a certain range, the greater the gap between MPCR the more conducive to the overall public goods contribution.

\section{Conclusion}

In this paper, we have examined the effects of MPCR heterogeneity in a two public goods experiment based on the reality. According to the results, we have analyzed the effects of MPCR heterogeneity.

The key finding is that cooperation efficiency is higher in the heterogeneous MPCR treatment than in the homogeneous treatment. We find that the contribution difference comes from two aspects: the increase of global public goods and the differences in MPCR. Subjects contribute more to the global public goods in the two global public goods treatment than in the single global public goods treatment. At the same time, they contribute to the public goods significantly less in the homogeneous MPCR treatment than in the heterogeneous MPCR treatment. We employ social identity theory and "choice bracketing" theory to explain why these behavioral differences occurred. Moreover, we explain cooperation behavior between groups from an innovative perspective of extrinsic reciprocity.

To solve the problems in cooperation caused by asymmetric income, we can expand the scope of 
regional cooperation so that, taken together, both sides' income from cooperation in the fields of two or more can change from asymmetric to symmetric.

Finally, we discuss future research questions. We learn that MPCR will affect the contribution to the public goods from previous experiments, and experiments in this paper confirm that the increase of public goods and setting the asymmetric MPCR are helpful to improving the efficiency of cooperation, but we need a further study on how much the difference of MPCR is when it can lead to the most efficient overall cooperation. We leave these issues for future research.

\section{References}

[1] Andreoni, James (1995) "Cooperation in public-goods experiments: kindness or confusion?" American Economic Review, Vol. 85, No. 4, pp. 891-904.

[2] Andreoni, James and B. Douglas Bernheim (2009) "Social Image and the 50-50 Norm: A Theoretical and Experimental Analysis of Audience Effects” Econometrica, Vol. 77, No. 5, pp. 1607-1636.

[3] Bernasconi, Michele, Luca Corazzini, Sebastian Kube, and Michel André Maréchal (2009) “Two are better than one!: Individuals' contributions to "unpacked" public goodss," Economics Letters, Vol. 104, No. 1, pp. 31 - 33.

[4] Chen, Yan and Sherry Xin Li (2009) "Group Identity and Social Preferences," American Economic Review, Vol. 99, No. 1, pp. 431-457. [5] Barrett, S. (1997). The strategy of trade sanctions in international environmental agreements. Resource and Energy Economics, 19, 345-361.

[6] Fischer, C. (2008). Feedback on household electricity consumption: A tool for saving energy? Energy Efficiency, 1, 79-104.

[7] Lohmann, S. (1997). Linkage politics. Journal of Conflict Resolution, 44, 38-67.

[8] Bolton, Gary E and Axel Ockenfels (2000) "ERC: A Theory of Equity, Reciprocity, and Competition,” American Economic Review, Vol. 90, No. 1, pp. 166-193.

[9] Nitta K. The effect of income heterogeneity in an experiment with global and local public goods[J]. University of Hawaii at Manoa, 2014. [10] Muller, Laurent, Martin Sefton, Richard Steinberg, and LiseVesterlund (2008) "Strategic behavior and learning in repeated voluntary contribution experiments," Journal of Economic Behavior \& Organization, Vol. 67, No. 3-4, pp. 782-793.

[11] Wachsman, Yoav (2002) "The effects of group interaction in a public goods experiment with two exchanges,” January. Working Paper.

[12] Keser, Claudia and Frans van Winden (2000) "Conditional Cooperation and Voluntary Contributions to Public Goods,” Scandinavian Journal of Economics, Vol. 102, No. 1, pp. 23-39.

[13] Tingley D, Tomz M. Conditional cooperation and climate change [J]. Comparative Political Studies, 2013: 0010414013509571.

[14] Fisher,J.,Isaac,R. M.,Schatzberg,J. W. and Walker,J. M.,1995,“Heterogeneous Demand for Public Goods: Behavior in the Voluntary Contributions Mechanism”,Public Choice,85 (3-4),pp.249 266.

[15]Ledyard,J. O.,1995,“Public Goods: A Survey of Experimental Research”,In: Kagel,J. H. and Roth,A. E.,eds. The Handbook of Experimental Economics Vol.1. Princeton: Princeton University Press,pp.111 194

[16] Anderson,L. R.,Mellor,J. M.andMilyo,J.,2008,“Inequality and Public Goods Provision: An 
Experimental Analysis”,Journal of Socio-Economics,37 (3),pp.1010 1028. (7) Ashley,R.,Ball,S. and Eckel,C.,200

[17] Chan, Kenneth S., Stuart Mestelman, Rob Moir, and R. Andrew Muller (1996) “The Voluntary Provision of Public Goods under Varying Income Distributions," Canadian Journal of Economics, Vol. 29, No. 1, pp. 54-69.

[18] Fehr,E. and K. M. Schmidt,2001,“Theories of Fairness and Reciprocity - Evidence and Economic Applications”, CEPR Discussion Paper.

[19] Gunnthorsdottir,A.,Houser,D. and McCabe,K.,2007,“Disposition,History and Contributions in Public Goods Experiments”,Journal of Economic Behavior \& Organization,62（2）,p304-315.

[20] Spraggon J, Oxoby R J. An experimental investigation of endowment source heterogeneity in two-person public goods games [J]. Economics letters, 2009, 104(2): 102-105. 